\section{The effect of 10 -week swimming and bosu exercises on dynamic balance parameter in 8-10 years old boys}

\section{8-10 yaş arası erkek çocuklarda 10 haftalık yüzme ve bosu egzersizlerinin dinamik denge parametresine etkisinin incelenmesi}

\author{
Hilal Kılınç Boz ${ }^{1}$ \\ H. Bayram Temur ${ }^{2}$ \\ Hacalet Mollaoğuları ${ }^{3}$
}

Özet

$\mathrm{Bu}$ çalışma 8-10 yaş arası erkek çocuklarda yüzme egzersiz ve bosu çalışmalarının dinamik dengeye etkisini incelemek amaciyla yapildı.

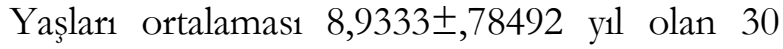
katilımc1 veli ve antrenörlerinden gönüllü katılımları ile ilgili aydınlanmıs onamları alınarak çalışmaya dahil edildi. Bunların 20' si egzersiz grubu diğer 10'u da kontrol grubudur. Egzersiz grubunun en az 1 yll yüzme eğitimi almış olmalarına ve haftada 3 gün düzenli olarak yüzme antrenmanı yapıyor olmalarına dikkat edildi. Egzersiz grubu rastgele yöntemle 2 gruba ayrrldı. Birinci gruba yüzme ve bosu çalışmaları, ikinci gruba ise sadece yüzme egzersizleri yaptırıldı. Bu çalışma 10 hafta süreyle uygulandı. Katılımcıların antropometrik ölçümler ile dinamik denge ölçümleri planlanan antrenman programı öncesi ve sonrası olmak üzere iki defa alındı. Çalışma Van Olimpik yüzme havuzunda uyguland. Verilerin analizinde SPSS 21 paket programı kullanıldı. Analizler sonucunda yüzme eğitimi alan grubun A (Anterior), PM (Posteromedial) ve PL (Posterolateral) ön test -

${ }^{1}$ Dr. Öğrt. Üyesi, Van Yüzüncüyıl Üniversitesi, Beden Eğitimi ve Spor, hilalkilinc@,msn.com
${ }^{2}$ Dr. Öğrt. Üyesi, Van Yüzüncüyıl Üniversitesi, Beden Eğitimi ve Spor, temurbay@,hotmail.com
${ }^{3}$ Dr. Öğrt. Üyesi, Muğla Sttkı Koçman Üniversitesi, Beden Eğitimi ve Spor, mhacalet@,mu.edu.tr 
Kılınç Boz, H., Temur, H. B, \& Mollaoğuları, H. (2019). 8-10 yaş arası erkek çocuklarda 10 haftalık yüzme ve bosu egzersizlerinin dinamik denge parametresine etkisinin incelenmesi. Journal of Human Sciences, 16(3), 807-814. doi:10.14687/jhs.v16i3.5727

was found that there was a significant difference $(\mathrm{p}<0.01)$ between the A (Anterior), PM (Poateromedial) and PL (Poaterolateral) pre-test and post-test measurements of the swimming group. It was determined that there was a significant difference $(p<0.01)$ between the PM and PL pretest - posttest measurements of the group receiving swimming and bosu training. There was no significant difference $(p<0.05)$ between the pre-test and post-test values of the selected variables.

Keywords: Swimming; Bosuball; Dynamic

Balance.

(Extended English summary is at the end of this document) son test ölçüm değerleri arasında anlamlı $(p<0,01)$ fark olduğu saptand. Yine yüzme ve bosu eğitimi alan grubun PM ve PL ön test - son test ölçüm değerleri arasında anlamlı $(p<0,01)$ fark olduğu belirlendi. Seçilmiş değişkenlerin ön test- son test ölçüm değerleri arasındaki farkların gruplar arasında anlamlı $(\mathrm{p}<0,05)$ bir farklillğın olmadığı görüldü.

Anahtar Kelimeler: Yüzme; Bosu; Dinamik Denge.

\section{Giriş}

Egzersiz, çocuğun fiziksel, zihinsel ve sosyal gelişimi için oldukça önemlidir. Çocuk spor aracıllğıyla, etrafi ile iletişim içerisindedir, kendine olan öz saygı düzeyinde gelişim gözlenir. Psikolojik olarak incelendiğinde, kendini kontrol altına alabilme, konuyu detaylı ele alabilme, başarıya odaklanma gibi birçok olumlu yönde gelişim sağlamaktadır.

Yüzme sporunun çocukların çok yönlü gelişim düzeyine olan faydalanı yapılan birçok bilimsel araştırmada ispatlanmıştır. Ayrıca bu çalışmalarda, çocukların bu branşa yönlendirilmesi konusunu önemle vurgulanmıştur (Sevim, 2002). Yüzme branşı diğer spor branşlanından birçok yönüyle ayrı ele alınmaktadır. Yüzme sporunun en önemli farkı, suyun üzerinde kalabilmek için kolların ve bacakların uyumlu olarak kullanılmasıyla yatay olarak hareketin yapılabilmesi için enerji harcanmasıdır. Bu boyutta ele alındığında "Belirli bir mesafeyi yüzebilmek için ihtiyac duyulan enerji, aynı mesafeyi koşmak için ihtiyac duyulan enerjinin dört katıdır" diye tanımlanabilmektedir.(Odabaş 2003).

Dinamik dengede ele alınacak önemli konulardan biri motor kontrol yeteneğinin sağlanmasıdır. Bu yeteneği geliştirmek, ani ivmelenme veya yavaşlama ile, vücudun yönünü farklı durum ve şartlarda değiştirerek hareket performansını arttırabilmek ile mümkündür. (Haynes, 2004).

Denge, bireyin ağırlık merkezinin belirli bir düzeyde tutulması ve bu durumun korunması ile ilişkilendirilmektedir. Spor bilimlerinin bakış açısı kapsamında ele alındığında ise denge; uygulanması istenen hareket için merkezi sinir sisteminin iş birliği ile iskelet-kas sisteminin birlikte koordine olması durumunu ele alan bir kabiliyettir (Muratli, 2003).

Yüzme sporunda temel motorik yetilerin gelişimi performans açısından önemli bir faktör olarak değerlendirilmektedir. Bu gelişimlere ilave olarak, kara antrenmanı adı altında çeşitli antrenman yöntemleri ile destek alınarak uygulanmaktadır. Bunlardan biri de bosu çalışmalarıdır. Bosu Toplanı denge gibi diğer motorik yetilerin gelişiminde de önemli katkı sağlamaktadır. Bu çalışmanın amacı; 8-10 yaş arası erkek çocuklarda yüzme egzersizi ve bosu çalışmalarının dinamik dengeye etkisinin incelenmesidir. 
Kılınç Boz, H., Temur, H. B, \& Mollaoğuları, H. (2019). 8-10 yaș arası erkek çocuklarda 10 haftalık yüzme ve bosu egzersizlerinin dinamik denge parametresine etkisinin incelenmesi. Journal of Human Sciences, 16(3), 807-814. doi:10.14687/jhs.v16i3.5727

\section{Yöntem}

Bu çalışma 8-10 yaş arası erkek çocuklarda yüzme egzersizi ve bosu çalışmalarının dinamik dengeye etkisini incelemek amacıyla yapıldı. 30 katılımcı veli ve antrenörlerinden gönüllü katılımları ile ilgili aydınlanmış onamları alınarak çalışmaya dahil edildi. Bunların 20' si egzersiz grubu diğer 10'u da kontrol grubudur. Egzersiz grubunun en az 1 yll yüzme eğitimi almış olmalarına ve haftada 3 gün düzenli olarak yüzme antrenmanı yapıyor olmalarına dikkat edildi. Egzersiz grubu rastgele yöntemle 2 gruba ayrıldı. Birinci gruba yüzme ve bosu çalışmaları, ikinci gruba ise sadece yüzme egzersizleri yaptırıldı. Bu çalışma 10 hafta süreyle uygulandı. Katılımcıların antropometrik ölçümler ile dinamik denge ölçümleri planlanan antrenman programı öncesi ve sonrası olmak üzere iki defa alındı. Çalışma Van Olimpik yüzme havuzunda uygulandı.

Deneklerin ağırlı ölçümleri \pm 100 gr hassasiyetli kantar ile yapılmıştır. Ölçüm; deneklerin üzerinde sadece şort varken, çıplak ayak ve anatomik duruş pozisyonunda 'kg' cinsinden alınmıştır.

Dinamik denge $\mathrm{Y}$ denge testi protokolü ile ölçülmüştür. Aralarında $120^{\mathrm{O}}$ açı olan anterior, anteromedial ve posterolateral yönlerdeki üç çizgi çizilmiştir. Sporculardan çizgilerin kesiştiği yer olan başlangıç noktasına elleri belinde olacak şekilde geçmesi istenmiştir. Daha sonra, dominant bacağ1 destek ayağı olacak şekilde diğer ayakucunu gidebildiği en uzak noktaya götürüp hafifçe dokundurup eski pozisyonuna gelmesi istenmiştir. Mesafeler mezüre yardımı ile ölçülmüştür. Antrenman Planı: Çalışma Van Olimpik yüzme havuzunda uygulanmıştır. Çalışmanın modeli ön test ve son test yöntemlerinden oluşmuştur. Yüzme+bosuball ve yüzme gruplarına her bir hafta da 3 gün olacak şekilde 10 hafta boyunca yüzme antrenmanları düzenli olarak yaptırılmıştır. Yüzme+bosball grubuna haftanın 2 günü 90 dakika yüzme antrenmanı haricinde bosuball alıştırmaları (direnç egzersizleri) yaptırılmıştır. Bosuball egzersizleri; egzersiz kapsamı, tekrar ve set sayısı ile belirlenmiştir. Set sayısı tüm hareketlerde 2 olarak belirlenmiştir. Setler arası dinlenme süresi 1 dakika olarak belirlenmiştir. 3. Egzersiz sonrası 5 dakikanın üstünde bir dinlenme süresi verilmiştir. Ilk hafta egzersizlere göre değişmekle beraber, tekrar sayısı 8-10 arasında başlayarak, 10. hafta sonunda 20-25 tekrar seviyesine ulaşmıştır. Katılımcılar antrenman yükündeki kademeli artışa uyum sağlamışlardır.

\section{Bosu Antrenmanı Çalışması}

\begin{tabular}{|l|l|}
\hline Egzersiz şiddeti & $\begin{array}{l}\text { Plank ve köprüde maksimalin ortalama \%25’i } \\
\text { Crunch ve oblik crunch hareketlerinde \%30-\%67 }\end{array}$ \\
\hline Egzersiz kapsamı & $\begin{array}{l}\text { Haftada } 3 \text { gün/günde } 20 \mathrm{dk} . \\
10 \text { haftada toplam } 30 \text { birim. }\end{array}$ \\
\hline Set/tekrar & 3set/15-25 tekrar, 3 set /30-40 sn. \\
\hline Dinlenme süresi & Setler aras1 1 dk. Dinlenme \\
\hline
\end{tabular}

\section{Bulgular}

Yüzme eğitimi alan grubun yaşları ortalamas $9,00 \pm, 67$ yll, Yüzme ve Bosu eğitimi alanların

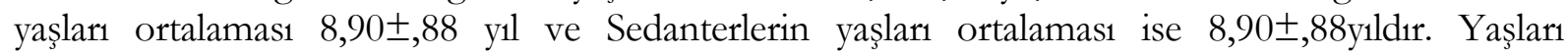
ortalamaları gruplar arasında anlamlı bir farklılık yoktur. Tüm deneklerin yaşları ortalaması ise

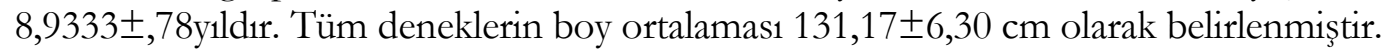


Kılınç Boz, H., Temur, H. B, \& Mollaoğuları, H. (2019). 8-10 yaș arası erkek çocuklarda 10 haftalık yüzme ve bosu egzersizlerinin dinamik denge parametresine etkisinin incelenmesi. Journal of Human Sciences, 16(3), 807-814. doi:10.14687/jhs.v16i3.5727

Tablo 1. Gruplara Göre Bazı Değişkenlerin Ön Test- Son Test Ölçüm Değerleri Ortalamaları Arasındaki Farkın Yönü Ve Anlamlılık Düzeyi.

\begin{tabular}{|c|c|c|c|c|c|c|c|}
\hline \multirow[t]{2}{*}{ Grup } & \multirow[t]{2}{*}{ Değişkenler } & \multirow[t]{2}{*}{$\mathbf{N}$} & \multirow{2}{*}{$\begin{array}{l}\text { Ön test } \\
\text { Ort. } \pm \text { Std. sp }\end{array}$} & \multirow{2}{*}{$\begin{array}{l}\text { Son test } \\
\text { Ort. } \pm \text { Std. sp }\end{array}$} & \multirow{2}{*}{$\begin{array}{l}\text { Ortalamalar } \\
\text { Arası Fark }\end{array}$} & \multirow[t]{2}{*}{$\mathbf{t}$} & \multirow[t]{2}{*}{$\mathbf{P}$} \\
\hline & & & & & & & \\
\hline \multirow{4}{*}{$\begin{array}{l}\text { Yüzme } \\
\text { eğitimi } \\
\text { alan }\end{array}$} & Vücut ağırlığ1 (kg) & 10 & $27,10 \pm 1,37$ & $27,10 \pm 1,37$ & 0 & ,000 & 1,000 \\
\hline & $\mathrm{A}(\mathrm{cm})$ & 10 & $66,10 \pm 3,84$ & $67,00 \pm 3,89$ & $-0,9$ & $-5,014$ & ,001 \\
\hline & $\mathrm{PM}(\mathrm{cm})$ & 10 & $65,70 \pm 3,97$ & $66,70 \pm 4,11$ & -1 & $-3,873$ & ,004 \\
\hline & $\mathrm{PL}(\mathrm{cm})$ & 10 & $67,00 \pm 3,94$ & $68,10 \pm 3,84$ & $-1,1$ & $-6,128$ & ,000 \\
\hline \multirow{4}{*}{$\begin{array}{l}\text { Yüzme ve } \\
\text { Bosu } \\
\text { eğitimi } \\
\text { alan }\end{array}$} & Vücut ağırlığ1 (kg) & 10 & $26,50 \pm 4,22$ & $26,80 \pm 4,18$ & $-0,3$ & $-1,964$ & ,081 \\
\hline & $\mathrm{A}(\mathrm{cm})$ & 10 & $68,10 \pm 3,54$ & $69,30 \pm 3,74$ & $-1,2$ & $-2,250$ & ,051 \\
\hline & $\mathrm{PM}(\mathrm{cm})$ & 10 & $67,50 \pm 3,75$ & $69,10 \pm 4,31$ & $-1,6$ & $-2,753$ & ,022 \\
\hline & $\mathrm{PL}(\mathrm{cm})$ & 10 & $67,40 \pm 3,10$ & $70,10 \pm 4,31$ & $-2,7$ & $-3,549$ & ,006 \\
\hline \multirow{4}{*}{ Sedanter } & Vücut ağırlığ1 (kg) & 10 & $33,20 \pm 4,89$ & $33,30 \pm 4,83$ & $-0,1$ &,- 557 & ,591 \\
\hline & $\mathrm{A}(\mathrm{cm})$ & 10 & $75,00 \pm 5,23$ & $75,20 \pm 4,96$ & $-0,2$ &,- 153 & ,882 \\
\hline & $\mathrm{PM}(\mathrm{cm})$ & 10 & $74,30 \pm 4,620$ & $74,30 \pm 4,47$ & 0 &, 000 & 1,000 \\
\hline & $\mathrm{PL}(\mathrm{cm})$ & 10 & $75,50 \pm 5,93$ & $75,60 \pm 5,78$ & $-0,1$ &,- 042 & ,968 \\
\hline
\end{tabular}

Tablo 1 gruplara göre incelendiğinde; Yüzme eğitimi alan kattlımcıların A(Anterior) ön test

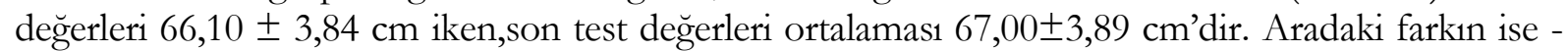
$0,9 \mathrm{~cm}$ olduğu görülmektedir. Aynı gruptaki PM (Posteromedial) öntest değerleri ortalamasının $65,70 \pm 3,97 \mathrm{~cm}$, son test ortalama değerlerinin ise $66,70 \pm 4,11 \mathrm{~cm}$, aradaki farkın ise $-1 \mathrm{~cm}$ olduğu saptanmıştır. Aynı grubun PL(Posterolateral) öntest değerleri ortalaması ise 67,00 $\pm 3,94 \mathrm{~cm}$, son test ortalama değerleri ise, $68,10 \pm 3,84 \mathrm{~cm}$, aradaki farkın ise $-1.1 \mathrm{~cm}$ olduğu belirlendi. Yüzme ve Bosu eğitimi alan katıllımcıların Öntest A değerleri ortalaması $68,10 \pm 3,54 \mathrm{~cm}$, son test ortalama değerleri $69,30 \pm 3,74 \mathrm{~cm}$,aradaki farkın ise $-1.2 \mathrm{~cm}$ olduğu görüldü.PM öntest değerleri ortalamasi ise $67,50 \pm 3,75 \mathrm{~cm}$,son test ortalama değerleri ise $69,10 \pm 4,31 \mathrm{~cm}$, farkın ise $-1.6 \mathrm{~cm}$ olduğu saptand1.PL öntest değerleri ortalaması ise , 67,40 $\pm 3,10 \mathrm{~cm}$,son test ortalama değerleri ise $70,10 \pm 4,31 \mathrm{~cm}$, aradaki fark ise 2,7 cm'dir.Aynı tablodaki sedanter grubun A öntest değerleri ortalamasına bakıldığında $75,00 \pm 5,23 \mathrm{~cm}$,son test ortalama değerleri $75,20 \pm 4,96 \mathrm{~cm}$, aradaki farkın -0.2 olduğu ortaya kondu. Aynı grubun PM öntest değerleri ortalaması ise 74,30 $\pm 4,620 \mathrm{~cm}$, son test ortalama değerleri ise $74,30 \pm 4,47 \mathrm{~cm}$, aradaki fark 0 olarak belirlendi. Aynı grubun PL değerleri öntest ortalamasi ise $75,50 \pm 5,93 \mathrm{~cm}$, sontest değerleri ortalamasi ise $75,60 \pm 5,78 \mathrm{~cm}$, aradaki fark $0.1 \mathrm{~cm}$ olarak belirlendi.

Tablo 2. Değişkenlerin gruplardaki ön test-son test farklarının karşılaştırılmasına göre ANOVA sonuçları.

\begin{tabular}{|c|c|c|c|c|c|c|}
\hline Değişkenler & $\begin{array}{l}\text { Varyansın } \\
\text { Kaynağ1 }\end{array}$ & $\begin{array}{l}\text { Kareler } \\
\text { Toplamı }\end{array}$ & S. Sapma & $\begin{array}{c}\text { Kareler } \\
\text { Ortalamas }\end{array}$ & $\mathrm{F}$ & $\mathrm{P}$ \\
\hline \multirow[t]{3}{*}{ Vücut ağırlığ1 } & Gruplar arası &, 467 & 2 & ,233 & 1,260 & 300 \\
\hline & Grup içi & 5,000 & 27 & ,185 & & \\
\hline & Toplam & 5,467 & 29 & & & \\
\hline \multirow[t]{3}{*}{ A } & Gruplar aras1 & 5,267 & 2 & 2,633 & ,390 & ,681 \\
\hline & Grup içi & 182,100 & 27 & 6,744 & & \\
\hline & Toplam & 187,367 & 29 & & & \\
\hline \multirow[t]{3}{*}{ PM } & Gruplar aras1 & 13,067 & 2 & 6,533 & ,576 & ,569 \\
\hline & Grup içi & 306,400 & 27 & 11,348 & & \\
\hline & Toplam & 319,467 & 29 & & & \\
\hline \multirow[t]{3}{*}{ PL } & Gruplar aras 1 & 34,400 & 2 & 17,200 & ,806 & ,457 \\
\hline & Grup içi & 575,900 & 27 & 21,330 & & \\
\hline & Toplam & 610,300 & 29 & & & \\
\hline
\end{tabular}


Kılınç Boz, H., Temur, H. B, \& Mollaoğuları, H. (2019). 8-10 yaş arası erkek çocuklarda 10 haftalık yüzme ve bosu egzersizlerinin dinamik denge parametresine etkisinin incelenmesi. Journal of Human Sciences, 16(3), 807-814. doi:10.14687/jhs.v16i3.5727

Tablo 2'de çalımaya dahil edilen gruplarda,belirlenen değişkenlerin öntest ve sontest ortalama değerleri arasındaki farklar açısından karşllaştırıldığında vücut ağırlı̆̆1, A (Anterior), PM (Posteromedial), PL (Posterolateral) öntest ve sontest değerleri arasındaki farkların gruplar arasında istatistiki olarak anlamlı fark olmadığı saptandı.

\section{Tartışma ve Sonuç}

Aggarwal ve diğerleri (2010) araştırmalarında kor stabilitesi ve denge antrenmanının statik ve dinamik denge performansı üzerindeki etkisini incelemişlerdir. Sonuç olarak statik dengenin istatiksel olarak anlamlı şekilde değiştiği ayrıca statik denge üzerinde kor stabilitesi antrenmanı etkisinin denge antrenmanına oranla daha büyük olduğunu bildirmişlerdir . Cosio-Lima ve diğerleri (2003) pilates topu ile gerçekleştirilen 5 haftalık kor stabilitesi ve denge antrenmanı ile geleneksel antrenmanı karşılaştırmıştır. Sonuç olarak, tek ayak denge değerlerinde kor stabilitesi ve denge antrenmanı yapan grubun pozitif ilerleme kaydettiğini bildirmiştir . Emery ve diğerleri (2005) sağlıklı adolesanlar üzerinde Wobble tahtası kullanarak gerçekleştirmiş oldukları 6 haftalık antrenman sonrasında statik denge ve dinamik denge değerlerinde gelişme olduğunu bildirmişlerdir. Ayrıca bu müdahale sonrası 6 aylık bir takip süresi gerçekleştirilmiş ve söz konusu antrenmanın katılımcıların sakatlık riskini azalttı̆g vurgulanmıştır.

Scibek (1999) pilates topu ile yaptırdıkları antrenman müdahalesi sonucu deney grubunun statik denge ve postür kontrolünde pozitif ilerleme görüldüğ̈nü bildirmişlerdir. Yaggie ve diğerleri (2006) 36 katıllmc1 ile 4 hafta süresince Bosu topu kullanarak yaptıkları antrenman sonrasında, deney grubunun statik denge kabiliyetinde anlamlı bir fark gözlemlemişlerdir. Bressel ve diğerleri (2007) kadın futbol, basketbol ve cimnastikçilerde statik ve dinamik dengenin karşılaşturması isimli çalışmalarında; statik dengeyi dominant ayak için 13,3 $\pm 1,3$ olarak, dominant olmayan ayak için $11,6 \pm 1,4$ olarak ortaya koymuşlardır. Basketbolcularda dominant ayak $13,6 \pm 1,1$ ve dominant olmayan ayak 14,5 $\pm 1,4$ olarak belirlemişlerdir. Cimnastikçilerde ise, dominant ayak $8,8 \pm 1,1$ ve dominant olmayan ayak 9,3 $\pm 1,3$ olarak belirlenmiştir (Bressel ve diğerleri, 2007). Aslan ve Livanelioğlu (2003) yoganın ve kalistenik egzersiz yöntemlerinin statik denge üzerinde elde edilen etkiler isimli çalışmalarında; gözler kapalı statik dengeye egzersizin etkili olduğunu ve istatistiki olarak $\mathrm{p}<0,01$ düzeyinde farklılık olduğunu belirtmişlerdir. Suveren Erdoğan ve diğerleri (2016) farklı boyutta uygulanan denge çalışmalarının voleybolcularda statik ve dinamik denge performansı üzerine etkileri isimli çalışmalarında 8 haftalık antrenman programına bağlı olarak deneklerin statik denge ön test ve son testleri arasında $\mathrm{p}<0,05$ düzeyinde anlamlı farklılıklar bulmuşlardır. Samson (2005), yaş ortalamaları 20 olan tenis sporcuları üzerinde kor antrenmanları ve dinamik denge arasındaki ilişkiyi incelemiştir. 13 sporcunun deney, 15 sporcunun kontrol grubunda yer aldığ1 çalışmada 5 haftalık kor antrenmanın etkisine Star Excursion Balance Test ile bakılmıştır. Sonuç olarak deney grubunun dinamik denge özelliğinde anlamlı bir gelişim gözlemlenmiştir. Sekendiz ve diğerleri (2010) sedanter kadınlar ile yaptıkları pilates antrenmanının sonucunda dinamik denge özelliği üzerinde dengez egzersizlerinin olumlu bir etkiye sahip olduğunu göstermişlerdir (Sekendiz ve diğerleri, 2010). Yıldızer (2014), statik denge performansının kuvvet platformu üzerinde anterioposterior ve medio-lateral tek-çift ayak, göz açık-kapalı duruşlarla belirlendiği çalışmada, futbolculara uygulanan 8 haftalık core stabilizasyon çalışmaları denge performansını geliştirse de, bu gelişim istatistiksel olarak anlam kazanmamıştur.

Suveren Erdoğan ve diğerleri (2016) farklı denge egzersizlerinin voleybolcularda statik ve dinamik denge performansı üzerine etkileri isimli çalışmalanı incelendiğinde 8 haftalık antrenman programına bağlı olarak deneklerin dinamik denge ön test ve son testleri arasında $\mathrm{p}<0,05$ düzeyinde anlamlı farklılıklar bulmuşlardır.

Literatür ile kıyaslandığında çalışmamız yapılan diğer çalışmalarla paralellik göstermektedir. Çalışmamız sonucunda düzenli bosu egzersizleri artan devamllık ilkesine göre haftada 3 siklıkla, her antrenman biriminde 60 dakika olarak uygulanmak üzere 10 hafta ve üzeri uygulanmasında sağlık ve performans getirisi açısından faydalar sağlayacağı düşünülmektedir. Buna ilaveten, zaman 
Kılınç Boz, H., Temur, H. B, \& Mollaoğuları, H. (2019). 8-10 yaş arası erkek çocuklarda 10 haftalık yüzme ve bosu egzersizlerinin dinamik denge parametresine etkisinin incelenmesi. Journal of Human Sciences, 16(3), 807-814. doi:10.14687/jhs.v16i3.5727

içerisinde uygulamalarda antrenman metodlarının çeşitliliğinin sağlanması uygulamalar açısından faydalar sağlayacağı söylenebilir.

\section{Kaynaklar}

Aggarwal, A., Zutshi, K., Munjal, J., Kumar, S., \& Sharma, V. (2010). Comparing stabilization training with balance training in recreationally active individuals. International Journal of Therapy and rehabilitation, 17(5), 244-253.

Aslan, U. B., \& Livanelioğlu, A. (2003). Hatha yoganın ve kalistenik egzersizlerin statik denge üzerindeki etkileri. Spor Bilimleri Dergisi, 14(2), 83-91.

Bressel, E., Yonker, J. C., Kras, J., \& Heath, E. M. (2007). Comparison of static and dynamic balance in female collegiate soccer, basketball, and gymnastics athletes. Journal of athletic training, 42(1), 42.

Cosio-Lima, L. M., Reynolds, K. L., Winter, C., Paolone, V., \& Jones, M. T. (2003). Effects of physioball and conventional floor exercises on early phase adaptations in back and abdominal core stability and balance in women. The Journal of Strength \& Conditioning Research, 17(4), 721-725

Emery, C. A., Cassidy, J. D., Klassen, T. P., Rosychuk, R. J., \& Rowe, B. H. (2005). Effectiveness of a home-based balance-training program in reducing sports-related injuries among healthy adolescents: a cluster randomized controlled trial. Canadian Medical Association Journal, 172(6), 749-754.

Gökmen, B. (2013). Denge geliştirici özel antrenman uygulamalarının 11 yaş erkek öğrencilerin statik ve dinamik denge performanslanna etkisi. Yüksek Lisans Tezi, Ondokuz Mayıs Üniversitesi Sağhk Bilimleri Enstitüsü Beden Eğitimi ve Spor Anabilim Dal, Samsun.

Gribble, P. A., Hertel J., Plisky, P. (2012). Using the Star Excursion Balance Test to Assess Dynamic Postural-Control Deficits and Outcomes in Lower Extremity Injury: A Literature and Systematic Review. Journal of Athletic Training, 47(3), 339 - 357

Haynes, W. (2004). Core stability and the unstable platform device. Journal of bodywork and movement therapies, 8(2), 88-103.

Muratl, S. (2003). Cocuk ve spor antrenman bilimi yaklaşımyla. Nobel Basımevi, 7-38.

Odabaş B. (2003). 12 Haftalık Yüzme Temel Eğitim Çalışmalarının 7-12 Yaş Gurubu Kız ve Erkek Yüzücülerin Fiziksel ve Motorsal Ozellikleri Uzerine Etkisi, Kocaeli, Kocaeli Üniversitesi Săglı. Bilimleri Enstitüsü, Yüksek Lisans Tezi.

Perrin, P., Deviterne, D., Hugel, F., \& Perrot, C. (2002). Judo, better than dance, develops sensorimotor adaptabilities involved in balance control. Gait \& posture, 15(2), 187-194.

Samson, K. M., Sandrey, M. A., \& Hetrick, A. (2007). A core stabilization training program for tennis athletes. Athletic Therapy Today, 12(3), 41-46.

Scibek, J. S. (1999). The effect of core stabilization training on functional performance in swimming (Doctoral dissertation, University of North Carolina at Chapel Hill).

Sekendiz, B., Cug, M., \& Korkusuz, F. (2010). Effects of Swiss-ball core strength training on strength, endurance, flexibility, and balance in sedentary women. The Journal of Strength \& Conditioning Research, 24(11), 3032-3040.

Sever, O. (2013). Futbolcuların fiziksel uygunluk düzeylerinin mevki ve yaş değişkenlerine göre incelenmesi. Yüksek Lisans Tezi, Gaði Üniversitesi Sağhlk Bilimleri Enstitüsü, Ankara.

Sevim, Y. (2002). Antrenman bilgisi. Nobel Yayın Dağıtım.

Suveren Erdoğan, C., Er, F., İpekoğlu, G., Çolakoğlu, T., Zorba, E., \& Çolakoğlu, F. F. (2017). Farklı denge egzersizlerinin voleybolcular da statik ve dinamik denge performansı üzerine etkileri. Spor ve Performans Araștırmalar Dergisi, 8(1), 11-18. 
Kılınç Boz, H., Temur, H. B, \& Mollaoğuları, H. (2019). 8-10 yaș arası erkek çocuklarda 10 haftalık yüzme ve bosu egzersizlerinin dinamik denge parametresine etkisinin incelenmesi. Journal of Human Sciences, 16(3), 807-814. doi:10.14687/jhs.v16i3.5727

Yaggie, J. A., \& Campbell, B. M. (2006). Effects of balance training on selected skills. Journal of strength and conditioning research, 20(2), 422.

Yildızer G. (2014). Effects of 8-week core stability training on junior male soccer players static balance performance. Yüksek Lisans Tezi. Orta Doğu Teknik Üniversitesi. Sosyal Bilimler Enstitüsü. Ankara.

\section{Extended English Summary}

The swimming branch is considered separately from many other sports branches. The most important difference of swimming sport is to spend energy to make horizontal movement by using arms and legs in harmony in order to stay on the water. Other differences are the factors necessary to minimize friction in water. In addition, water has a repressive effect on the respiratory system, which makes it difficult to breathe. Therefore, the energy required to swim a distance is four times the energy required to run the same distance için (Odabaş 2003).

Dynamic equilibrium is one of the issues to be considered important is to provide motor control capability. To improve this ability, sudden acceleration or deceleration, to change the direction of the body in different conditions and conditions to improve the performance of the movement, adapted for unstable and dynamic exercises, and many exercises can be applied with a large number of exercise equipment can be applied with them (Haynes, 2004).

The development of basic motor skills in swimming is considered as an important factor in terms of performance. In addition to these developments, it is implemented with the support of various training methods under the name of ground training. One of them is bosu studies. Bosu balls also contribute to the development of other motoric properties such as balance. Because the bosular multi-faceted movement and applied movement have the characteristics of feeling every pain. In addition, they can be used in every age group is another advantage of the bosular. This study was conducted to investigate the effect of swimming exercise and bosuball studies on dynamic balance in 8-10 years old boys. The study was carried out with a total of 30 subjects, 20 of whom were between 8-10 years of age, and 10 of them were sedentary. The study was carried out for 10 weeks and enlightened consent was obtained from the participants and their coaches about their voluntary participation. The participants were randomly divided into 3 groups. The first group $(\mathrm{n}=10)$ had swim and bosu exercises, and the second group $(\mathrm{n}=10)$ had only swimming exercises. In the study, anthropometric measurements and dynamic balance measurements were taken.

The balance is an important factor to maintain the body composition needed to keep the sporting performance at the highest level. Therefore, equilibrium forms the basis of dynamic spores with sudden changes in movement patterns. All sports branches have a certain balance (Gökmen, 2013; Altay, 2001).

Learning a sport branch and training for a long time improves static and dynamic postural control in daily life. Proper balance control in performing motor capabilities depends on synergic muscles, which minimize body weight changes in sporty activities while maintaining vertical position (Perrin et al., 2002).

Weight of the subjects were measured with \pm 100 gr. Measurement; On the subjects only the shorts were present, bare feet and anatomical posture were taken as en $\mathrm{kg}$ den. Y Balance Test was used to determine the dynamic balance performances of the study group. In the Y-balance test application, the individual needs to maintain the body's stability with the support leg and with the other foot reaching the maximum position in different directions and returning to the first position. The participant was asked to reach three different directions (anterior, posterior medial and posterior lateral) at the last point where he could reach the maximum. The maximum reach was determined as the distance reached by the elongation foot at the last point. If the participant lifts 
Kılınç Boz, H., Temur, H. B, \& Mollaoğuları, H. (2019). 8-10 yaş arası erkek çocuklarda 10 haftalık yüzme ve bosu egzersizlerinin dinamik denge parametresine etkisinin incelenmesi. Journal of Human Sciences, 16(3), 807-814. doi:10.14687/jhs.v16i3.5727

her foot off the ground, moves it away from the center point and presses the support foot to reach the point where it extends beyond the touch, it is not accepted and reapplied (Gribble et al., 2012).

Stellar (2014), static equilibrium performance on the force platform anterio-posterior and medio-lateral single-double foot, eye open-closed stance determined in the study, 8-week core stabilization studies applied to footballers improve the balance performance, this development is not statistically significant ( Yildızer, 2014). Suveren Erdoğan et al. (2016) found significant differences at the $\mathrm{p}<0.05$ level between the dynamic balance pre-test and post-tests of the subjects according to the 8 -week training program in their studies on the effects of different balance exercises on static and dynamic balance performance in volleyball players.

As a result of the study, no statistically significant difference was observed in the pretest and posttest values of Body Weight, A, PM, PL data obtained, and our study show parallel with other studies. The result of our study; It is thought that it will change in a positive way by increasing the duration or frequency of training. 